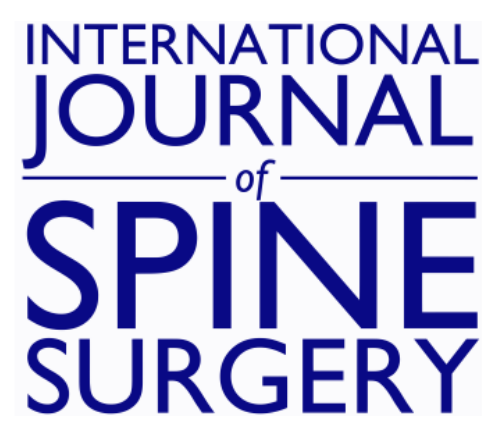

\title{
A Review of Unilateral Biportal Endoscopic Decompression for Degenerative Lumbar Canal Stenosis
}

Jwo-Luen Pao

Int J Spine Surg 2021, 15 (suppl 3) S65-S71

doi: https://doi.org/10.14444/8165

http://ijssurgery.com/content/15/suppl_3/S65

This information is current as of April 26, 2023.

Email Alerts Receive free email-alerts when new articles cite this article. Sign up at:

http://ijssurgery.com/alerts

The International Journal of Spine Surgery

2397 Waterbury Circle, Suite 1,

Aurora, IL 60504, Phone: +1-630-375-1432 


\title{
A Review of Unilateral Biportal Endoscopic Decompression for Degenerative Lumbar Canal Stenosis
}

\author{
JWO-LUEN PAO, MD ${ }^{1,2}$ \\ ${ }^{l}$ Department of Orthopedic Surgery, Far-Eastern Memorial Hospital, New Taipei, Taiwan; ${ }^{2}$ Longhwa University of Science \& Technology, Taoyuan, Taiwan
}

\begin{abstract}
Background: The unilateral biportal endoscopic (UBE) technique provides minimally invasive decompression for degenerative lumbar canal stenosis (DLCS). With appropriate control of the hydrostatic pressure of normal saline irrigation, the surgery can be performed in a clear and magnified surgical field through 2 small surgical wounds.

Methods: A review of published literature in PubMed was performed to identify studies of UBE decompression for DLCS. The outcome measures include operation time, length of hospital stay, estimated blood loss, visual analog scale (VAS) scores for back and leg pain, Oswestry Disability Index (ODI), and the Macnab criteria.

Results: A total of 76 relevant studies were retrieved through the PubMed search. After screening, 15 studies comprising 6 case series, 6 comparative studies, and 3 randomized controlled trials were included in this review. Significant improvements in pain and neurological symptoms were obtained in all studies. In the 6 case series studies, the outcome measures were extracted from each study and summarized. The follow-up periods ranged from 8.6 to 29 months. The operation time was 72.0 min. The VAS score for leg pain was reduced from 7.8 to 1.7, and the VAS score for back pain was reduced from 5.8 to 1.7. The ODI was reduced from 63.0 to 20.7 , and $87.3 \%$ of patients reported good to excellent outcomes according to the Macnab criteria. The complication rates ranged from $5.5 \%$ to $13.8 \%$, with dural tear having the highest incidence rate. In the comparative studies and randomized controlled trials examining the UBE, microscopic, microendoscopic, and uniportal endoscopic techniques, the UBE technique showed treatment results that were comparable with the others. Compared with the microscopic technique, the UBE technique resulted in significantly less tissue trauma and quicker recovery with less wound pain, lower serum creatine kinase and C-reactive protein levels, and lower ODI in the very early postoperative period. The UBE technique also provided adequate decompression with less facet joint destruction than all the other decompression techniques.

Conclusions: The UBE technique is safe and effective for decompression of DLCS. Along with its efficacy in decompression, this technique is capable of preserving segmental stability. However, a long-term comparative study is required to verify this hypothesis.
\end{abstract}

Special Issue

Keywords: minimally invasive surgery, biportal endoscopic spine surgery, lumbar canal stenosis

\section{INTRODUCTION}

Degenerative lumbar canal stenosis (DLCS) is the most common indication for spinal surgery in the elderly population. ${ }^{1}$ Wide laminectomy with or without concomitant fusion was the standard surgical procedure for decades. ${ }^{2-4}$ This classical approach required a sizable surgical wound and an extensive soft tissue dissection, which could lead to fatty degeneration, atrophy, and weakness of the paraspinal muscles. ${ }^{5,6}$ The randomized controlled trials showed that fusion added little value to decompression for DLCS. ${ }^{7,8}$ Therefore, the optimal treatment for DLCS could be the balance between adequate decompression and preservation of segmental stability.

In 1983, Kambin and Gellman first proposed the concept of percutaneous lateral discectomy to minimize the soft tissue damage caused by surgical exposure. ${ }^{9}$
This concept helped inspire the development of minimally invasive spine surgery. Various minimally invasive techniques were developed to overcome the limitations of small surgical wounds and to provide effective decompression of the neural tissues. Some of the benefits to patients of these techniques were small surgical wounds, less soft tissue damage, less postoperative pain, faster recovery, and the potential for better long-term results as compared to the open techniques. ${ }^{10}$

Unilateral biportal endoscopic (UBE) decompression is a percutaneous endoscopic technique not confined by the working tube or the working channel. It is performed through 2 small separated surgical wounds on the right or left side of the spinous process. One portal is used for the endoscope and saline inflow, and the other is used for instrument passage and saline outflow. Unilateral laminotomy is followed by bilateral decompression under the endoscope. Through continuous normal 
saline irrigation and a high-definition endoscope, the surgeon can perform very precise decompression in a clear and magnified endoscopic surgical field. This novel technique has attracted a lot of attention from spine surgeons who are interested in minimally invasive spine surgery.

In this study, we reviewed the literature and summarized the clinical outcomes of UBE decompression for DLCS.

\section{METHODS}

\section{Literature Search and Screening}

A PubMed search of English literature was conducted using the terms "biportal endoscopic spinal surgery" and "lumbar spine." We conducted a thorough review of the literature and manually checked the reference lists. We included only studies of lumbar canal decompression. Studies of lumbar disc herniation, foraminal stenosis, and cervical and thoracic disorders; studies with mixed diagnoses; and studies combined with fusion were excluded. Studies without functional outcome evaluation were also excluded. Studies from the same institution were carefully reviewed to avoid any possible overlap in data collection. Only the studies that provided the most comprehensive data were included

\section{Data Extraction}

Data were extracted for information including first author name, publication year, study type, number of patients, and follow-up period. The collected outcome measures were operative time, length of hospital stay, estimated blood loss, visual analog scale (VAS) scores for back pain and leg pain, Oswestry Disability Index
(ODI), outcomes according to the Macnab criteria, and complications. All data were summarized for analysis.

\section{RESULTS}

\section{Study Selection}

A total of 76 potentially relevant studies were retrieved through the PubMed search. After the first screening of titles and abstracts, 31 studies were excluded. The second screening was a detailed full-text investigation of the remaining 45 studies. Following the second screening, another 31 studies were excluded: 10 technical notes, 9 with mixed diagnoses, 6 for complication management, 3 case reports, 1 with only a study protocol proposal, 1 with only a learning curve analysis, and 1 in which no tool was used for the outcome evaluation. Therefore, 14 studies fulfilled the inclusion criteria. ${ }^{1-24}$ Of the 14 studies, 2 studies conducted by the same authors using the same patient population were published sequentially as a preliminary report and a formal report. Only the formal report was included. ${ }^{14}$ In addition, 2 studies ${ }^{25,26}$ were found from a manual check of the reference lists of the 45 studies that met the inclusion criteria. A total of 15 studies comprising 6 case series, 6 comparative studies, and 3 randomized controlled trials were included in this review (Figure S1).

\section{Case Series}

The 6 case series studies included 386 patients with an average age of $62.2^{15,20,22,24-26}$ The results are summarized in Table 1 . The overall weighted operation time was $72.0 \mathrm{~min}$. The intraoperative blood loss was reported in only 1 study because the amount was minimal and diluted by the continuous irrigation of

Table 1. Summary of case series studies.

\begin{tabular}{|c|c|c|c|c|c|c|c|c|c|c|c|c|}
\hline Study & Study Design & $\mathbf{n}$ & Age, $y$ & Follow-Up, mo & $\begin{array}{l}\text { OP Time/ } \\
\text { Level, min }\end{array}$ & $\begin{array}{l}\text { Blood } \\
\text { Loss, } \\
\text { mL }\end{array}$ & $\begin{array}{c}\text { Hospital } \\
\text { Stay }\end{array}$ & $\begin{array}{l}\text { VAS Leg } \\
\text { Pre-OP/ } \\
\text { PO }\end{array}$ & $\begin{array}{l}\text { VAS Back } \\
\text { Pre-OP/ } \\
\text { PO }\end{array}$ & $\begin{array}{c}\text { ODI } \\
\text { Pre-OP/PO }\end{array}$ & $\begin{array}{c}\text { Macnab, } \\
\%\end{array}$ & Complications \\
\hline Soliman $2015^{27}$ & Prospective & 104 & 52.0 & 28.0 & 62.8 & 60 & $15.9 \mathrm{~h}$ & NR & NR & $64.2 / 3.1$ & 87 & $5.8 \%$; dural tear (6) \\
\hline $\begin{array}{l}\text { Torudom \& } \\
\text { Dilokhuttakarn } \\
2016^{26}\end{array}$ & Retrospective & 30 & 56.0 & 24.0 & 98.3 & NR & $3.16 \mathrm{~d}$ & $8.3 / 2.3$ & $7.2 / 2.4$ & $65.2 / 24.0$ & 83 & $6.6 \%$; transient paresthesia (2) \\
\hline Eum et al $2016^{24}$ & Retrospective & 58 & 63.4 & 13.8 & 68.9 & NR & NR & $8.3 / 2.4$ & NR & $67.2 / 24.3$ & 81 & $\begin{array}{l}\text { 13.8\%; postoperative headache } \\
\text { (3), dural tear (2), transient } \\
\text { leg numbness (2), epidural } \\
\text { hematoma (1) }\end{array}$ \\
\hline Kim \& Choi $2018^{22}$ & Retrospective & 55 & 70.7 & 29.0 & 53.0 & NR & NR & $7.7 / 1.7$ & NR & $67.4 / 19.3$ & 81 & $\begin{array}{c}5.5 \% \text {; dural tear (2); epidural } \\
\text { hematoma (1) }\end{array}$ \\
\hline Kim \& Jung $2019^{20}$ & Retrospective & 58 & 63.1 & 18.0 & NR & NR & NR & $7.9 / 1.6$ & $7.1 / 1.9$ & NR & 93.1 & $\begin{array}{c}\text { 10.3\%; incomplete } \\
\text { decompression (4); dural } \\
\text { tear (2) }\end{array}$ \\
\hline Pao et al $2020^{15}$ & Retrospective & 81 & 70.2 & 8.6 & 89.0 & NR & NR & $7.3 / 0.9$ & $4.3 / 4.3$ & $54.6 / 14.6$ & 93.8 & $\begin{array}{l}\text { 8.6\%; dural tear (4); transient } \\
\text { motor weakness (1); } \\
\text { incomplete decompression } \\
\text { (1); epidural hematoma (1) }\end{array}$ \\
\hline $\begin{array}{l}\text { Overall weighted } \\
\text { values }\end{array}$ & & & 62.2 & & 72.0 & & & $7.8 / 1.7$ & $5.8 / 1.7$ & $63.0 / 20.7$ & 87.3 & \\
\hline
\end{tabular}

Abbreviations: NR, not recorded; ODI, Oswestry Disability Index; OP, operation; PO, postoperative; VAS, visual analog scale. 
normal saline. The average hospital stay was reported in only 2 studies. The follow-up periods ranged from 8.6 to 29 months. The VAS score for leg pain was reduced from 7.8 to 1.7 in 5 studies. The VAS score for back pain was reduced from 5.8 to 1.7 in only 3 of the 6 studies. The ODI was reduced from 63.0 to 20.7 in 5 of the 6 studies. All studies reported that improvement was significant and sustained at the final follow-up. Moreover, $87.3 \%$ of patients reported good to excellent results according to the Macnab criteria.

There were a total of 32 complications reported in these 6 studies with complication rates ranging from $5.5 \%$ to $13.8 \%$. The dural tear (16 cases) was the most frequently encountered complication, followed by transient neurological symptoms (5 cases), incomplete decompression ( 5 cases), epidural hematoma ( 3 cases), and postoperative headache ( 3 cases). One dural tear was recognized during the operation and was repaired directly using endoscopic techniques. All the other dural tears were treated conservatively with no neurological sequels. Reoperation was required for 5 patients due to incomplete decompression, recurrence of neurological symptoms, and epidural hematoma.

\section{Comparative Studies}

A total of 6 comparative studies were identified and included in this review (Table 2).

Two retrospective studies and 1 prospective study compared the clinical results between the microscopic
(MS) technique and the UBE technique. ${ }^{13,16,23}$ Each study group was small (30-54 patients). Two studies had only short-term follow-up (12 and 14.5 months), and 1 study had midterm follow-up (more than 2 years). Faster recovery was observed with the UBE technique as well as a significantly lower VAS score, ODI, serum creatine kinase level, and serum C-reactive protein (CRP) level during the very early postoperative period. ${ }^{13}$ However, at final follow-up, clinical results including operation time, improvement in VAS for leg and back pain, and ODI showed no significant difference between these 2 techniques. Significantly earlier ambulation and shorter hospital stay were noted in the UBE group. ${ }^{16}$ Complications, including dural tear and epidural hematoma, were similar between groups. Among the 237 patients in these 3 studies, there was only 1 surgical site infection in the MS group. ${ }^{13}$ Reoperations due to epidural hematoma were required for 2 patients, 1 in the MS group and 1 in the UBE group. ${ }^{16}$

Choi and Kim conducted a retrospective comparative study comparing UBE decompression, MS decompression, and spine fusion. ${ }^{21}$ The VAS scores for back and leg pain were greatly reduced in each group with no significant differences between groups. The need for blood transfusion was significantly less in the UBE group (0\%) than in the MS group (33.3\%) and the fusion group (85.4\%). The serum CRP level was also significantly lower in the UBE group than in the MS and fusion groups. The complication rates were similar

Table 2. Summary of comparative studies.

\begin{tabular}{|c|c|c|c|c|c|c|c|c|c|c|c|c|c|}
\hline Authors & Study Design & Technique (n) & Follow-Up, mo & Age, $y$ & $\begin{array}{c}\text { OP Time/ } \\
\text { Level, } \\
\text { min }\end{array}$ & $\begin{array}{l}\text { VAS Leg } \\
\text { Pre-OP }\end{array}$ & $\begin{array}{l}\text { VAS } \\
\text { Leg } \\
\text { PO }\end{array}$ & $\begin{array}{c}\text { VAS Back } \\
\text { Pre-OP }\end{array}$ & $\begin{array}{c}\text { VAS } \\
\text { Back } \\
\text { PO }\end{array}$ & $\begin{array}{c}\text { ODI } \\
\text { Pre-OP }\end{array}$ & $\begin{array}{l}\text { ODI } \\
\text { PO }\end{array}$ & $\begin{array}{c}\text { Macnab, } \\
\% \%\end{array}$ & Complications \\
\hline $\begin{array}{r}\text { Kim et al } \\
2020^{13}\end{array}$ & Retrospective & $\begin{array}{l}\text { UBE (30) } \\
\text { MS (30) }\end{array}$ & 12 & NR & $\begin{array}{l}58.1 \\
62.4\end{array}$ & $\begin{array}{l}7.1 \\
7.3\end{array}$ & $\begin{array}{l}1.2 \\
1.3\end{array}$ & $\begin{array}{l}\text { NR } \\
\text { NR }\end{array}$ & $\begin{array}{l}\mathrm{NR} \\
\mathrm{NR}\end{array}$ & $\begin{array}{l}71.2 \\
72\end{array}$ & $\begin{array}{l}23.5 \\
24.7\end{array}$ & $\begin{array}{l}76.7 \\
73.3\end{array}$ & $\begin{array}{l}\text { UBE: dural tear (1) } \\
\text { MS: dural tear (2), } \\
\text { SSI (1) }\end{array}$ \\
\hline $\begin{array}{l}\text { Min et al } \\
\quad 2020^{16}\end{array}$ & Retrospective & UBE (54) & 27.2 & 65.74 & NR & 7.38 & 1.48 & 5.27 & 1.64 & 60.4 & 15.4 & NR & $\begin{array}{l}\text { UBE: dural tear (1), } \\
\text { hematoma (1), } \\
\text { re-OP (1) } \\
\text { MS: dural tear (1), } \\
\text { hematoma (1), } \\
\text { re-OP (2) }\end{array}$ \\
\hline $\begin{array}{l}\text { Heo et al } \\
2018^{23}\end{array}$ & Prospective & $\begin{array}{l}\text { UBE (46) } \\
\text { MS (42) }\end{array}$ & 14.5 & 65.8 & $\begin{array}{l}61.1 \\
58.9\end{array}$ & $\begin{array}{l}7.97 \\
7.76\end{array}$ & $\begin{array}{l}1.98 \\
2.04\end{array}$ & $\begin{array}{l}7.04 \\
6.76\end{array}$ & $\begin{array}{l}2.07 \\
2.21\end{array}$ & $\begin{array}{l}57.98 \\
59.43\end{array}$ & $\begin{array}{l}21.98 \\
22.59\end{array}$ & $\begin{array}{l}\text { NR } \\
\text { NR }\end{array}$ & $\begin{array}{l}\text { UBE: dural tear (1), } \\
\text { hematoma (1) } \\
\text { MS: dural tear (1), } \\
\text { hematoma (2) }\end{array}$ \\
\hline $\begin{array}{l}\text { Choi \& Kim } \\
2019^{21}\end{array}$ & Retrospective & $\begin{array}{l}\text { UBE (35) } \\
\text { MS (30) } \\
\text { Fusion (48) }\end{array}$ & 24.5 & NR & NR & 6.3 & 2.2 & 6.8 & 2.8 & NR & NR & NR & $\begin{array}{l}\text { Dural tear (2); root } \\
\text { injury (1) }\end{array}$ \\
\hline $\begin{array}{l}\text { Heo et al } \\
2019^{18}\end{array}$ & Retrospective & $\begin{array}{l}\text { UBE (37) } \\
\text { UE (27) }\end{array}$ & 12.5 & $\begin{array}{l}66.7 \\
67.3\end{array}$ & $\begin{array}{l}62.4 \\
61.6\end{array}$ & $\begin{array}{l}8.05 \\
7.93\end{array}$ & $\begin{array}{l}2.16 \\
1.89\end{array}$ & $\begin{array}{l}7 \\
7\end{array}$ & $\begin{array}{l}1.95 \\
1.8\end{array}$ & $\begin{array}{l}58.68 \\
56.7\end{array}$ & $\begin{array}{l}23.14 \\
23.54\end{array}$ & $\begin{array}{l}\text { NR } \\
\text { NR }\end{array}$ & $\begin{array}{l}\text { UBE: dural tear (1), } \\
\text { hematoma (1) } \\
\text { UE: dural tear (1), } \\
\text { hematoma (1) } \\
\text { MS: dural tear (2), } \\
\text { transient weakness } \\
\text { (1), hematoma (2) }\end{array}$ \\
\hline $\begin{array}{l}\text { Ito et al } \\
\qquad 2021^{11}\end{array}$ & Retrospective & UBE (42) & 6.7 & 66.3 & 57 & 3.9 & 1.0 & 3.9 & 1.3 & 23.5 & 11.3 & NR & $\begin{array}{l}\text { MED: hematoma } \\
\text { (2), dural tear (8), } \\
\text { re-OP (2) }\end{array}$ \\
\hline & & MED (139) & 6.9 & 65.0 & 51 & 4.5 & 1.2 & 3.7 & 1.5 & 23.3 & 12.5 & NR & UBE: dural tear (2) \\
\hline
\end{tabular}

Abbreviations: BE, biportal endoscopic; MED, microendoscopic; MS, microscopic; NR, not recorded; ODI, Oswestry Disability Index; OP, operative; PO, postoperative; SSI, surgical site infection;UBE, unilateral biportal endoscopic; UE, uniportal endoscopic; VAS, visual analog scale. 
between the groups, but wound infections were noted only in the fusion group.

Heo et al conducted a retrospective study comparing the MS, UBE, and uniportal endoscopic (UE) techniques. ${ }^{18}$ The VAS score for back pain was significantly higher in the MS group on the first postoperative day. However, the VAS scores for back and leg pain and ODI at final follow-up showed no significant difference between groups.

Ito et al conducted a retrospective comparative study comparing microendoscopic (MED) and UBE techniques. ${ }^{11}$ The laminotomy area evaluated by 3-dimensional computed tomography was significantly smaller in the UBE group, with a higher facet joint preservation rate on both the ipsilateral and contralateral sides. The VAS scores for back and leg pain, ODI, and the results of EuroQol's EQ-5D questionnaire were significantly improved in both groups. with no significant differences between them. Complications occurred more frequently in the MED group, but the difference was insignificant.

\section{Randomized Controlled Trial}

Two randomized controlled trials compared shortterm treatment results between MS and UBE techniques. ${ }^{14,17}$ The UBE technique resulted in significantly shorter operation time, less drainage, less opioid use, and shorter hospital stays. However, the clinical outcomes showed no significant difference between groups in terms of VAS score and ODI at final follow-up.

Another randomized controlled trial examined the treatment results between MED and UBE techniques periodically for 2 years. ${ }^{12}$ The UBE techniques exhibited significantly shorter operation time, less estimated blood loss, and shorter hospital stays. The UBE technique was significantly superior in ODI and Zurich Claudication Questionnaire results for all periods. At the end of the second year, a significantly higher percentage of excellent results was noted in the UBE group (63\% vs. $29 \%$ ) according to the modified Macnab criteria.

\section{Effectiveness of Decompression}

Unilateral laminotomy for bilateral decompression is a well-established decompression technique that was used routinely in all the studies included in this review. The efficacy of decompression was usually evaluated by comparing the preoperative and postoperative cross-sectional dural area using magnetic resonance imaging. Significant dural expansion of up to $200 \%$ could be achieved using the UBE technique. ${ }^{15}$ The decompression effect of the UBE technique was significantly better than that of the UE technique and comparable to that of the MS technique, although clinical outcomes were similar among these 3 techniques. ${ }^{18,23}$

\section{Preservation of Segmental Stability}

Preservation of the facet joint was reported in 1 case series study and 1 comparative study. When the decompression is done using unilateral laminotomy for bilateral decompression, there is usually more facet joint destruction on the approach side than the contralateral side. With the UBE technique, the percentage of facet joint preservation was $84.2 \%$ on the approach side and $92.9 \%$ on the contralateral side. ${ }^{15}$ Compared with the MED technique, the facet preservation rate was similar on the approach side, but the UBE technique had a significantly higher preservation rate for the contralateral facet joints. ${ }^{11}$

Postdecompression segmental instability was studied in 2 comparative studies. There was no significant change in slippage or dynamic percentage of slip at the final follow-up in the UBE groups in both studies. However, when compared with the MS technique, the difference in the dynamic percentage of slip was insignificant in 1 study ${ }^{16}$ and significant in the other. ${ }^{13}$

\section{DISCUSSION}

UBE decompression has been used as a minimally invasive surgical technique to treat lumbar disc herniation and spinal canal stenosis for more than 10 years. ${ }^{24,25,27,28}$ With recent advancements in endoscopic technology and surgical instruments, UBE techniques have been successfully applied to treat various disorders in the cervical, thoracic, and lumbar spines. ${ }^{29-31}$

For DLCS, adequate decompression can be achieved with the UBE technique. Up to $200 \%$ increments in the cross-sectional dura area after operation have been reported. ${ }^{15}$ The efficacy of decompression was found to be better than that of UE techniques and comparable with MS decompression. ${ }^{18}$ The UBE technique has several advantages over other minimally invasive surgical techniques. First, surgeons can handle the surgical instruments almost the same way as in open surgeries, without restriction from a rigid working channel or a tubular retractor. ${ }^{32}$ Second, the diameter of the endoscope used in UBE techniques is only $4 \mathrm{~mm}$. The surgeon can advance the scope very close to the lesion, even into the contralateral lateral recess or intervertebral foramen. The closer the surgeon can get to the lesion, the smaller the laminotomy window that is needed for an adequate decompression. The study by Ito et al proved that the same decompression effect was 
achieved using UBE and MED techniques, while a smaller laminotomy was required for the UBE technique. ${ }^{11} \mathrm{Heo}$ et al also reported a smaller facetectomy angle in the UBE technique compared with the UE technique. ${ }^{18}$

To avoid postdecompression segmental instability, the integrity of facet joints must be preserved as much as possible when pursuing a complete neural decompression. A biomechanical study demonstrated that facet joint destruction greater than $50 \%$ could lead to segmental instability. ${ }^{33}$ With the UBE technique, more than $80 \%$ of the facet joint on the approach side and more than $90 \%$ of the facet joint on the contralateral side could be preserved. ${ }^{15}$ These preservation rates are higher than those seen with the MED technique, especially on the contralateral side. ${ }^{11}$ There was no evidence of postdecompression segmental instability found after UBE decompression for DLCS. ${ }^{13,16}$ Therefore, these findings support the idea that decompression alone is enough, and fusion surgeries may be avoided to preserve the mobility of the lumbar spine.

One of the most important benefits of minimally invasive spine surgery is faster recovery due to minimal injury to the soft tissue and paraspinal muscles. When compared with the standard MS technique, the UBE technique caused less tissue trauma, which was reflected by lower serum creatine kinase and CRP levels in the very early postoperative period. However, the difference was not significant after 1 month. The UBE technique also resulted in significantly less postoperative pain, which led to early ambulation and shorter hospitalization. ${ }^{13,16}$

The most frequently encountered complication in UBE decompression was dural tear, with an incidence that varied from $1.5 \%$ to $9.7 \%{ }^{34-37}$ While most of the dural tears were very small and could be managed conservatively, a dural tear larger than $10 \mathrm{~mm}$ would need to be repaired to prevent cerebrospinal fluid leakage and its sequels. ${ }^{35}$ Direct dural repair under endoscope is possible but technically demanding. Therefore, a variety of alternative methods have been proposed to help effectively seal the dural tears. ${ }^{35-37}$ Like the UE technique, the UBE technique depends on continuous normal saline irrigation during the surgical procedure. The hydrostatic pressure may propagate upward through the dural tear and damage the central nervous system. ${ }^{38,39}$ Under circumstances without a dural tear, Choi et al suggested interrupting endoscopic procedures lasting longer than $30 \mathrm{~min}$ to avoid increasing intracranial pressure. ${ }^{38}$ Therefore, if the dural tear cannot be sealed effectively during the surgery or the surgeon is not confident about completing the surgical procedure effectively in a short period, the endoscopic surgery should be abandoned or converted to open surgery.

Epidural hematoma is not uncommon after UBE decompression for DLCS. Bleeding control in UBE techniques is very effective by using the hydrostatic pressure of the normal saline, radiofrequency wands, and bone wax. Sometimes surgeons misinterpret perfect hemostasis and assume no bleeding will continue after the surgical procedure. However, the bleeding does continue in the small dead space when the hydrostatic pressure stops. Although most epidural hematomas are asymptomatic, they may lead to inferior treatment results. Revision surgery might be necessary if canal encroachment is more than $50 \%$ with concomitant symptoms. ${ }^{40}$

All minimally invasive surgical techniques are technically demanding. The learning curve for MED, UBE, and UE techniques has been estimated to be 30, 58, and 100 cases, respectively, for surgeons with no endoscopic spine surgery experience. ${ }^{41-43}$ However, for a surgeon familiar with MED or UE techniques, the learning curve for the UBE technique may be significantly less steep. After overcoming the learning curve, the UBE technique can be a very powerful surgical technique to treat various degenerative spine disorders in the lumbar, thoracic, and cervical spines.

In conclusion, the UBE technique is safe and effective with promising and encouraging treatment outcomes for DLCS in relieving pain and neurological symptoms. However, the follow-up period in most of the studies included in this review is relatively short. Therefore, to effectively assess the theoretical advantages of the UBE technique on segmental instability and paraspinal muscles, a long-term comparative study is required.

\section{REFERENCES}

1. Weinstein JN, Tosteson TD, Lurie JD, et al. Surgical versus nonsurgical therapy for lumbar spinal stenosis. $N$ Engl $\mathrm{J} \mathrm{Med.}$ 2008;358(8):794-810. doi:10.1056/NEJMoa0707136.

2. Grob D, Humke T, Dvorak J. Degenerative lumbar spinal stenosis. Decompression with and without arthrodesis. J Bone Joint Surg Am. 1995;77(7):1036-1041. doi:10.2106/00004623199507000-00009.

3. Lee SY, Kim T-. H, JK O, Lee SJ, Park MS. Lumbar stenosis: a recent update by review of literature. Asian Spine J. 2015;9(5):818-828. doi:10.4184/asj.2015.9.5.818.

4. Rompe JD, Eysel P, Zöllner J, Nafe B, Heine J. Degenerative lumbar spinal stenosis. Long-term results after undercutting decompression compared with decompressive laminectomy alone or with instrumented fusion. Neurosurg Rev. 1999;22(2-3):102-106. doi:10.1007/s101430050040.

5. Gille O, Jolivet E, Dousset V, et al. Erector spinae muscle changes on magnetic resonance imaging following lumbar surgery through a posterior approach. Spine. 2007;32:1236-1241. doi:10.1097/BRS.0b013e31805471fe. 
6. Gejo R, Matsui H, Kawaguchi Y, Ishihara H, Tsuji H. Serial changes in trunk muscle performance after posterior lumbar surgery. Spine. 1999;24(10):1023-1028. doi:10.1097/00007632199905150-00017.

7. Peul WC, Moojen WA. Fusion for lumbar spinal stenosis--safeguard or superfluous surgical implant. $N$ Engl J Med. 2016;374(15):1478-1479. doi:10.1056/NEJMe1600955.

8. Försth P, Ólafsson G, Carlsson T, et al. A randomized, controlled trial of fusion surgery for lumbar spinal stenosis. $N$ Engl J Med. 2016;374(15):1413-1423. doi:10.1056/NEJMoa1513721.

9. Kambin P, Bracer MD. Percutaneous posterolateral discectomy. Clin Orthop Relat Res. 1987;223(NA):145. doi:10.1097/00003086-198710000-00016.

10. Banczerowski P, Czigléczki G, Papp Z, Veres R, Rappaport HZ, Vajda J. Minimally invasive spine surgery: systematic review. Neurosurg Rev. 2015;38(1):11-26. doi:10.1007/s10143-014-0565-3.

11. Ito Z, Shibayama M, Nakamura S, et al. Clinical comparison of unilateral biportal endoscopic laminectomy versus microendoscopic laminectomy for single-level laminectomy: a single-center, retrospective analysis. World Neurosurg. 2021;148:e581-e588. doi:10.1016/j.wneu.2021.01.031.

12. Aygun H, Abdulshafi K. Unilateral biportal endoscopy versus tubular microendoscopy in management of single level degenerative lumbar canal stenosis: a prospective study. Clin Spine Surg. 2021;34(6):E323-E328. doi:10.1097/BSD.0000000000001122.

13. Kim H-S, Choi S-H, Shim D-M, Lee I-S, Oh Y-K, Woo Y-H. Advantages of new endoscopic Unilateral Laminectomy for Bilateral Decompression (ULBD) over conventional microscopic ULBD. Clin Orthop Surg. 2020;12(3):330-336. doi:10.4055/cios19136.

14. Park S-. M, Park J, Jang HS, et al. Biportal endoscopic versus microscopic lumbar decompressive laminectomy in patients with spinal stenosis: a randomized controlled trial. Spine J. 2020;20(2):156-165.

15. Pao J-L, Lin S-M, Chen W-C, Chang C-H. Unilateral biportal endoscopic decompression for degenerative lumbar canal stenosis. J Spine Surg. 2020;6(2):438-446. doi:10.21037/jss.2020.03.08.

16. Min W-. K, Kim J-. E, Choi D-. J, Park EJ, Heo J. Clinical and radiological outcomes between biportal endoscopic decompression and microscopic decompression in lumbar spinal stenosis. $J$ Orthop Sci. 2020;25(3):371-378. doi:10.1016/j.jos.2019.05.022.

17. Kang T, Park SY, Kang CH, Lee SH, Park JH, Suh SW. Is biportal technique/endoscopic spinal surgery satisfactory for lumbar spinal stenosis patients?: a prospective randomized comparative study. Medicine (Baltimore. 2019;98(18):e15451):18:. doi:10.1097/ MD.0000000000015451.

18. Heo DH, Lee DC, Park CK. Comparative analysis of three types of minimally invasive decompressive surgery for lumbar central stenosis: biportal endoscopy, uniportal endoscopy, and microsurgery. Neurosurg Focus. 2019;46(5):E9. doi:10.3171/2019.2.FOCUS197.

19. Park S-. M, Kim G-. U, Kim H-. J, et al. Is the use of a unilateral biportal endoscopic approach associated with rapid recovery after lumbar decompressive laminectomy? A preliminary analysis of a prospective randomized controlled trial. World Neurosurg. 2019;128:e709-e718. doi:10.1016/j.wneu.2019.04.240.

20. Kim N, Jung SB. Percutaneous unilateral biportal endoscopic spine surgery using a 30-degree arthroscope in patients with severe lumbar spinal stenosis: a technical note. Clin Spine Surg. 2019;32(8):324-329. doi:10.1097/BSD.0000000000000876.

21. Choi D-J, Kim J-E. Efficacy of biportal endoscopic spine surgery for lumbar spinal stenosis. Clin Orthop Surg. 2019;11(1):82-88. doi:10.4055/cios.2019.11.1.82.
22. Kim J-E, Choi D-J. Clinical and radiological outcomes of unilateral biportal endoscopic decompression by $30^{\circ}$ arthroscopy in lumbar spinal stenosis: Minimum 2-year follow-up. Clin Orthop Surg. 2018;10(3):328-336. doi:10.4055/cios.2018.10.3.328.

23. Heo DH, Quillo-Olvera J, Park CK. Can percutaneous biportal endoscopic surgery achieve enough canal decompression for degenerative lumbar stenosis? Prospective case-control study. World Neurosurg. 2018;120:e684-e689. doi:10.1016/j.wneu.2018.08.144.

24. Hwa Eum J, Hwa Heo D, Son SK, Park CK. Percutaneous biportal endoscopic decompression for lumbar spinal stenosis: a technical note and preliminary clinical results. J Neurosurg Spine. 2016;24(4):602-607. doi:10.3171/2015.7.SPINE15304.

25. Soliman HM. Irrigation endoscopic decompressive laminotomy. A new endoscopic approach for spinal stenosis decompression. Spine J. 2015;15(10):2282-2289. doi:10.1016/j. spinee.2015.07.009.

26. Torudom Y, Dilokhuttakarn T. Two portal percutaneous endoscopic decompression for lumbar spinal stenosis: preliminary study. Asian Spine J. 2016;10(2):335-342. doi:10.4184/ asj.2016.10.2.335.

27. Soliman HM. Irrigation endoscopic discectomy: a novel percutaneous approach for lumbar disc prolapse. Eur Spine J. 2013;22(5):1037-1044. doi:10.1007/s00586-013-2701-0.

28. Choi CM, Chung JT, Lee SJ, Choi DJ. How I do it? Biportal endoscopic spinal surgery (BESS) for treatment of lumbar spinal stenosis. Acta Neurochir (Wien. 2016;158(3):459-463. doi:10.1007/ s00701-015-2670-7.

29. Choi D-J, Kim J-E, Jung J-T, et al. Biportal endoscopic spine surgery for various foraminal lesions at the lumbosacral lesion. Asian Spine J. 2018;12(3):569-573. doi:10.4184/asj.2018.12.3.569.

30. Heo DH, Sharma S, Park CK. Endoscopic treatment of extraforaminal entrapment of 15 nerve root (far out syndrome) by unilateral biportal endoscopic approach: Technical report and preliminary clinical results. Neurospine. 2019;16(1):130-137. doi:10.14245/ ns.1938026.013.

31. Song K-S, Lee C-W, Moon J-G. Biportal endoscopic spinal surgery for bilateral lumbar foraminal decompression by switching surgeon's position and primary 2 portals: a report of 2 cases with technical note. Neurospine. 2019;16(1):138-147. doi:10.14245/ ns.1836330.165.

32. Eun SS, Eum JH, Lee SH, Sabal LA. Biportal endoscopic lumbar decompression for lumbar disk herniation and spinal canal stenosis: a technical note. J Neurol Surg A Cent Eur Neurosurg. 2017;78(4):390-396. doi:10.1055/s-0036-1592157.

33. Abumi K, Panjabi MM, Kramer KM, Duranceau J, Oxland T, Crisco JJ. Biomechanical evaluation of lumbar spinal stability after graded facetectomies. Spine. 1990;15(11):1142-1147.10.1097/00007632-199011010-00011 10.1097/00007632-199011010-00011

34. Hong Y-H, Kim S-K, Suh D-W, Lee S-C. Novel instruments for percutaneous biportal endoscopic spine surgery for full decompression and dural management: a comparative analysis. Brain Sci. 2020;10(8):E516. doi:10.3390/brainsci10080516.

35. Kim J-E, Choi D-J, Park EJ. Risk factors and options of management for an incidental dural tear in biportal endoscopic spine surgery. Asian Spine J. 2020;14(6):790-800. doi:10.31616/ asj.2019.0297.

36. Heo DH, JS H, Lee DC, Kim HS, Chung HJ. Repair of incidental durotomy using sutureless nonpenetrating clips via biportal endoscopic surgery. Global Spine J. 2020. doi:10.1177/2192568220956606. 
37. Park H-. J, Kim S-. K, Lee S-. C, Kim W, Han S, Kang S-. S. Dural tears in percutaneous biportal endoscopic spine surgery: anatomical location and management. World Neurosurg. 2020;136:e578-e585. doi:10.1016/j.wneu.2020.01.080.

38. Choi G, Kang H-. Y, Modi HN, et al. Risk of developing seizure after percutaneous endoscopic lumbar discectomy. $J$ Spinal Disord Tech. 2011;24(2):83-92.

39. Lin C-. H, Lin S-. M, Lan T-. Y, Pao J-. L. Pneumocephalus with conscious disturbance after full endoscopic lumbar diskectomy. World Neurosurg. 2019;131:112-115. doi:10.1016/j. wneu.2019.07.200.

40. Kim J-. E, Choi D-. J, Park EJ. Evaluation of postoperative spinal epidural hematoma after biportal endoscopic spine surgery for single-level lumbar spinal stenosis: clinical and magnetic resonance imaging study. World Neurosurg. 2019;126:e786. doi:10.1016/j.wneu.2019.02.150.

41. Choi D-. J, Choi C-. M, Jung J-. T, Lee S-. J, Kim Y-. S. Learning curve associated with complications in biportal endoscopic spinal surgery: challenges and strategies. Asian Spine J. 2016;10(4):624-629. doi:10.4184/asj.2016.10.4.624.

42. Nomura K, Yoshida M. Assessment of the learning curve for microendoscopic decompression surgery for lumbar spinal canal stenosis through an analysis of 480 cases involving a single surgeon. Global Spine J. 2017;7(1):54-58. doi:10.1055/s-0036-1583943.
43. Lee C-W, Yoon K-J, Kim S-W. Percutaneous endoscopic decompression in lumbar canal and lateral recess stenosis - the surgical learning curve. Neurospine. 2019;16(1):63-71. doi:10.14245/ ns.1938048.024.

Funding: The author(s) received no financial support for the research, authorship, and/or publication of this article.

Declaration of Conflicting Interests: The authors report no conflicts of interest in this work.

Corresponding Author: Jwo-Luen Pao, MD, Department of Orthopedic Surgery, Far-Eastern Memorial Hospital, New Taipei, Taiwan; jwoluenpao@gmail. com

Published 31 December 2021

This manuscript is generously published free of charge by ISASS, the International Society for the Advancement of Spine Surgery. Copyright (C) 2021 ISASS. To see more or order reprints or permissions, see http:// ijssurgery.com. 